\title{
Curriculum Reform of Management Based on OBE Education Concept
}

\author{
Yuling Sun \\ Guangzhou College of Commerce, Guangzhou 510000, China \\ 1017733822@qq.com
}

\begin{abstract}
Apply OBE Results-Oriented Education Concept to the curriculum reform of management from two aspects. On the one hand, we should reform the evaluation method of management teaching results from the perspective of assessment program. On the other hand, we should reshape the teaching concepts and methods of management from the perspective of teaching implementation. Through the construction of a pyramid implementation framework, it is guided by one core target, guaranteed by two important conditions and supported by three key points. This can not only improve the students' learning achievements, but also improve the teaching quality of professional teachers, which is more conducive to promoting the curriculum reform of Application-oriented Undergraduate Education in China.
\end{abstract}

Keywords: Results-Oriented Education; management; teaching effect; curriculum reform.

\section{Introduction}

Management is a basic core course for freshmen majoring in economics and management. The course is characterized by strong comprehensiveness, high relevance with other disciplines, rich content, fast knowledge updating, and high degree of combination of theory and practice. Outcomes-based Education refers to the education mode based on learning output. Based on the concept of OBE, the curriculum reform of management requires schools and teachers to take the learning results of management course as the ultimate goal, cooperate with the diversified and flexible personalized learning requirements, let students complete the challenges of self-realization through the learning process of management, and then feedback the results to improve the course design.

At present, in the research of management curriculum reform, Guohua Yu et al. (2019) proposed that innovation and entrepreneurship education should be integrated into management course teaching from the perspective of curriculum content reform [1]. Biyan Wang et al. (2019) proposed the reform of teaching methods, adopting sandwich teaching method, that is, in the process of teaching, students' collective and individual learning stages are interspersed [2]. Xinxing Wu (2019) proposed the reform from the perspective of internationalization, including five dimensions of teaching module, teaching form, assessment method, teaching resources and teaching language [3]. Xiaojuan Wen, etc. (2018) and He Ma, etc. (2018) mainly analyze from the dimensions of management major, curriculum reform, practice curriculum [4,5]. Based on the research of these scholars, this paper starts from the Application-oriented Undergraduate Education and transforms the abstract OBE concept into a set of concrete and operational pyramid implementation framework to further supplement and improve the current management curriculum reform.

\section{Practical Exploration of Curriculum Reform to Management based on OBE Concept}

\subsection{Reform the Evaluation Method of Management Teaching Results from the Perspective of Assessment Scheme}

Making a clear management teaching goal is the core of the reform. In the traditional management teaching, the most common means of testing students' learning outcomes is the examination, especially the closed-book exam. This kind of assessment method is characterized by limited proposition, standardized test questions, accurate scores, etc., which leads students to get good results through rote memorization, killing students to truly pass textbook knowledge. Based on OBE, the 
management course is no longer the traditional assessment method of "one test and one score", but runs the assessment throughout the whole teaching process. Through the establishment of a diversified assessment system dominated by "ability orientation", flexible and diverse assessment methods are adopted to truly reflect the comprehensive knowledge and skill level of students and objectively test their mastery of what they have learned, fully mobilize the enthusiasm and initiative of students to learn, and cultivate the application-oriented talents with real innovative spirit.

Specifically, the "Management" total score assessment method consists of two parts: the usual score and the final exam score, namely: total score $=$ (usual grade $\times$ percentage $)+($ final exam score $\times$ percentage). The usual grade assessment includes attendance, classroom questions, usual homework, stage tests, note-taking, course experiments, classroom performance, and online selfstudy results, etc. Teachers should generally maintain a certain ratio of excellent, good, medium and bad in their usual grades, and resolutely put an end to the one-size-fits-all, human-influenced and fullfledged phenomenon. Students who are likely to be assessed as unqualified in their usual grades should be warned in a timely manner. Those who fail to meet the standard can cancel the exam qualification. The final exam adopts the assessment method of "small papers + groups to complete projects or tasks together". According to the content of the lectures, combined with the students' personal interests, students are required to select the frontier issues related to management and write a course paper, and provide a paper check report. The group project is a group of students who are free to form the same number of groups, each group members clear division of labor, and jointly complete the analysis of enterprise cases.

\subsection{Reconstructing the Teaching Concepts and Methods of Management from the Perspective of Teaching Implementation}

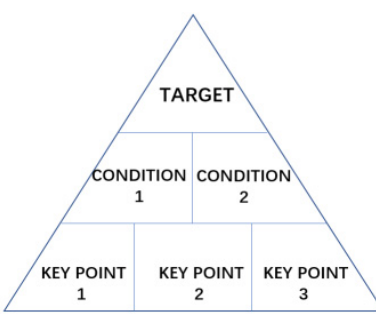

Fig. 1 Management pyramidal implementation framework based on OBE concept

As shown in Figure 1, the specific scheme of management curriculum reform based on OBE concept can be summarized as one core target, two important conditions and three key points.

\subsubsection{One Core Target}

The core target is to systematically grasp the basic theory, technology and method of management work through careful study of various management theories and practices at home and abroad, adhere to the combination of theory with practice, and be able to observe and analyze the management problems in real life with the management principles and methods learned, and finally improve the ability of comprehensive analysis and problem-solving.

\subsubsection{Two Important Conditions}

Condition 1 is to establish a clear and feasible blueprint for learning outcomes. First of all, teachers should make an accurate analysis of students' learning characteristics and needs. The management course is mainly aimed at the professional basic courses offered by freshmen. It is necessary to change the teaching mode that they used to rely on teachers and focus on Teachers' teaching, guide them to focus on learning and improve their participation in the classroom. Secondly, teachers should set up corresponding learning objectives for students in each class, let students know the knowledge objectives, ability objectives and quality objectives of management courses, and encourage and help students to set their own learning objectives.

Condition 2 is to create a successful environment and provide suitable conditions and opportunities for students to achieve expected results. Specifically, although the classroom is not within the enterprise, the classroom can simulate and reproduce the enterprise scene, that is, use case teaching. 
Teachers need to select the representative content of each chapter of management, according to the learning objectives of each lesson, so that students can be placed in specific situations, divided into different groups, and use brainstorming and other methods to think and discuss, form group views, and then interact and communicate with other groups to achieve the purpose of enlightening thinking and enlightening theory. The teacher's role is to lead students to summarize and discuss the viewpoints and rise to the height of theory. Through the collision of knowledge and opinions between students and teachers, case teaching not only helps students to be willing to take the initiative to learn, to think, and to deepen their understanding of the theory, but also helps students to learn, to transform knowledge into the ability to analyze and solve problems, to shape students' individual achievement team's spirit of cooperation, and to spur teachers constantly supplement the new teaching content of the subject. It realizes a win-win situation for both students and teachers.

\subsubsection{Three Key Points}

The first key point is to ensure that all students can achieve the expected results through learning management courses, but not necessarily at the same time and in the same way. Each student has individual differences, cognitive level, learning ability and their own quality also have a great gap, so teachers need to teach students according to their aptitude. Teachers understand their students through classroom observation and analysis and after class talk. According to the usual test results and classroom performance, teachers should master the students' ability to receive knowledge. They should analyze the reasons for the students with poor performance, such as low thinking level, limitations of learning style, problems of learning habits, obstacles of learning motivation, etc. Teachers take different ways of adjustment, consciously to point out training, to help students develop their strengths and avoid weaknesses. Teachers also need to constantly improve the methods according to the feedback of students in a semester of teaching.

The second key point is that the success of learning promotes more successful learning. Strengthening theory can be used in the teaching of management course. First of all, set up the learning objectives of management in stages. Specifically, it is to set up the general objectives and sub objectives for students to learn management course, and decompose the sub objectives into many small objectives. The overall goal is to achieve the top of the pyramid in Figure 1. In order to ensure every student can reach the target, it needs to be subdivided into every class. Teachers set a clear and specific small goal, and check the achievement of the goal through various testing methods. Students who achieve small goals should be encouraged in time or increase their usual performance. Students who fail to achieve goals should also be punished with negative reinforcement. Teachers should feedback their learning results to students in time, affirm good learning behaviors, and help students find problems, analyze the causes and correct them in time.

The third key point is to develop a teaching mode suitable for the management course. At present, the biggest problem of management classroom teaching is that the teaching mode of teachers is single, the whole class becomes teachers' own "talk", while students are dull in the classroom and active in the classroom. These common classroom phenomena reflect that the current mainstream management teaching model is still teacher-centered and does not really translate into student-centered. According to the relevant survey results, there is a difference between teachers and students in the degree of concentration in a class. The attention of students in class is U-shaped, that is, the beginning and end of a class is the most concentrated time period, but the lowest in class. The teacher teaching is exactly the opposite, which is expressed as inverted U-shaped, that is, the performance in class is the best. According to this, the effective teaching of BOPPPS can be improved to the most suitable teaching model for management.

BOPPPS effective teaching is divided into six parts: First, Bridge-in adopts the combination of Phoenix strategy and situational edification teaching, that is, introducing curriculum related cases or interesting management stories, arousing students' learning enthusiasm and attracting students' attention in a relaxed and pleasant beginning. Second, objective / outcome is determined by goal guided teaching, which can be divided into cognitive domain, emotional domain and motor skill domain by referring to the Bloom Education Goal Classification Method. Teachers should set clear classroom learning objectives for students, take attainable and evaluable as standards to encourage, 
correct and strengthen students' learning. Third, the pre assessment adopts the question inquiry teaching mode, in which the teacher throws out questions and mainly tests them in the form of questions and answers and sharing, so as to detect the students' pre-school knowledge reserve and interest points, and prepare for adjusting the difficulty and progress of the follow-up knowledge content. Fourthly, participation learning continues to adopt the question inquiry teaching mode, focusing on inquiry. Let students participate in the teaching through thinking and group discussion, and adopt the way of interaction between teachers and students. The discussion topics set by teachers should not only be limited to the problems of primary cognition, but also rise to the problems of advanced cognition from shallow to deep, which can stimulate students' management thinking. Fifthly, post assessment adopts the question inquiry teaching mode, which is mainly compared with the pretest part. It can form a questionnaire to test the knowledge points with the help of learning interaction platform, which is helpful for teachers to understand the students' mastery of management knowledge and learning effect in this lesson. Sixth, the summary adopts the teaching mode of transfer acceptance. and the course ends with a powerful ending of leopard tail strategy. Teachers can review the summary of this lesson with students. In order to consolidate what they have learned in the classroom, teachers can use the self-study guidance mode to arrange extended thinking questions, homework and followup courses for students, guide students to self -summarize by building mind map and knowledge tree after class, and self-study the knowledge of the next class.

\section{Summary}

The core idea of introducing OBE concept into the course of management is to improve the classroom teaching design and teaching implementation through teachers, fully reflect the main position of students, do not distinguish the level of students, give full play to the subjective initiative of all students through multiple flexible personalized teaching, help all students to achieve the sub objectives of each class, and then feedback the results to guide teachers to improve the original curriculum design and teaching, and ultimately achieve the overall goal of students' learning management courses. Through long-term learning and reinforcement, students learn not only easyto-forget information and one-sided knowledge; but an understanding of management theory and practical activities; and the correct way to learn knowledge that can be retained in the learning process for a long time. The ability to apply to the realities of life, and the ability to analyze and solve problems, and the positive pioneering spirit and innovative spirit.

\section{References}

[1]. Guohua $\mathrm{Yu}$, Qingqing $\mathrm{Hu}$, Lijuan Wan. Research on the integration of innovation and entrepreneurship education into the teaching of management. Journal of Kaifeng Institute of education. Vol. 39 (2019) No. 8, p. 128-129.

[2]. Biyan Wang, Sijing Tu, Xinyan Gan. SWOT analysis and strategy of sandwich teaching method applied to management course. Journal of Guangxi University of traditional Chinese medicine. Vol. 22 (2019) No. 3, p. 89-93.

[3]. Xinxing $\mathrm{Wu}$. Teaching and practice of management in the perspective of internationalization. Journal of Changchun Normal University. Vol. 38 (2019) No. 9, p. 186-188.

[4]. Xiaojuan Wen, Yanqing Liang. Research on the mixed teaching mode based on the OBE concept -- Taking the course of management as an example. Higher financial education research. Vol. 21(2018) No. 1, p. 45-49+55.

[5]. He Ma, Hui Wang. Research on the teaching reform of management course in Colleges and Universities under the concept of OBE. Curriculum education research. Vol. 46(2018) No. 10, p. 249. 